\title{
Maternal and fetal outcome of pregnancy related hypertension in Mettu Karl Referral Hospital, Ethiopia
}

\author{
Eshetu Seyom ${ }^{1}$, Mubarek Abera ${ }^{2}$, Million Tesfaye ${ }^{3^{*}}$ and Netsanet Fentahun ${ }^{4}$
}

\begin{abstract}
Background: Hypertensive disorders of pregnancy are the most common causes of adverse maternal \& perinatal outcomes. Such investigations in resource limited settings would help to have great design strategies in preventing maternal and perinatal morbidity and mortality.

Aim: To determine management outcome and factor associated with pregnancy related hypertensive disorder in Mettu Karl Referral Hospital, Mettu, Ethiopia.

Method: A retrospective study deign was conducted at Mettu Karl Referral Hospital from $1^{\text {st }}$ January 2010 to December $1^{\text {st }} 2013$ by reviewing medical records and logbooks. Descriptive, binary and multiple logistic regression analysis were used. A 95\% Cl and P-value of $<0.05$ were considered statistically significant.

Result: The magnitude of pregnancy related hypertensive disorder was $2.4 \%$. Majority $82.6 \%$ of the mothers were in the age range between 18 to 34 year with a mean age and standard deviation (SD) of 24.4 (SD \pm 5.12 ). Sever preeclampsia was the most prevalent diagnosis made to $35.5 \%$ of the mother, followed by $19 \%$ cases of eclampsia and $12.4 \%$ of HELLP. Fetal management outcomes indicates 120.37 perinatal mortality per 1000 deliveries and a stillbirth rate of 10.2\%, low birth weight of $30.5 \%$, and low APGAR score of $18.5 \%$, abortion $10.7 \%$ and preterm delivery $31.4 \%$.

Conclusion: In this study severe preeclampsia is the most common of all pregnancy related hypertension disorders followed by Eclampsia. Fetal complications like low Apgar score and preterm deliveries were statistically significant and associated with fetal management outcomes.
\end{abstract}

Keywords: Gestational, Hypertension, Preeclampsia, Eclampsia, Low resource country

\section{Introduction}

Preeclampsia is a hypertensive disorder of pregnancy, which usually manifests after 20 weeks of gestation with hypertension and proteinuria,while hypertension being defined with blood pressure at least $140 \mathrm{~mm} \mathrm{Hg}$ for systolic and/or $90 \mathrm{~mm} \mathrm{Hg}$ for diastolic on at least two occasions and at least 4-6 hrs apart in women known to be normotensive beforehand [1-3]. Severe hypertension is considered if sustained rises in blood pressure to the level of $>=160 \mathrm{~mm} \mathrm{Hg}$ for systolic), and/or $110 \mathrm{~mm} \mathrm{Hg}$ for diastolic, $[1,3,4]$. When convulsions occur in addition

\footnotetext{
* Correspondence: mtesfaye1@gmail.com

${ }^{3}$ Department of Anesthesia, Jimma University, Jimma, Ethiopia

Full list of author information is available at the end of the article
}

to these signs, of preeclampsia the condition is referred to as eclampsia [5].

Preeclampsia is primarily a disorder of nulliparous, but multiparous pregnant women with a new partner have an elevated risk of preeclampsia similar to that of nulliparous women [6]. Delivery of placenta is the only treatment yet known, indicating placenta is the primary sponsor to the pathogenesis of preeclampsia [7].

Following the drama of hypertensive disorders during pregnancy, $12-22 \%$ of all pregnancies, have a tragic story $[8,9]$. Increased mortality and morbidity as a result of Preeclampsia during pregnancy is not only a terror to the mother but also to the fetus [10]. Preeclampsia has hang around till this century and continues being public health concern in both developed and developing countries [11]. 
Table 1 Perinatal outcome of mothers with hypertensive disorder of pregnancy

\begin{tabular}{|c|c|c|c|c|c|c|}
\hline \multirow[t]{3}{*}{ Perinatal outcome } & \multicolumn{6}{|c|}{ Type of hypertension (Hypertensive disorder of pregnancy) } \\
\hline & Mild preeclampsia & Sever preeclampsia & HELLP & Eclampsia & Gestational & Chronic \\
\hline & No (\%) & No (\%) & No $(\%)$ & No (\%) & No (\%) & No (\%) \\
\hline \multicolumn{7}{|c|}{ Fetal weight (grams) } \\
\hline Wt. $\geq 2500$ & $13(72.2)$ & $26(60.5)$ & $3(20.0)$ & $15(65.2)$ & $14(87.5)$ & $4(66.7)$ \\
\hline Wt. $=1000-2499$ & $5(27.8)$ & $12(27.9)$ & $9(60.0)$ & $6(26.1)$ & $1(6.2)$ & $0(0.0)$ \\
\hline \multicolumn{7}{|l|}{ Fetal outcome } \\
\hline Stil birth & $2(11.1)$ & $6(14.0)$ & $3(20.0)$ & $0(0.0)$ & $0(0.0)$ & $0(0.0)$ \\
\hline Low APGAR/<7/ & $2(11.1)$ & $7(16.7)$ & $4(26.7)$ & $3(13.0)$ & $3(18.8)$ & $1(16.7)$ \\
\hline Abortion & $0(0.0)$ & $5(11.6)$ & $3(20.0)$ & $2(8.7)$ & $1(6.2)$ & $2(33.3)$ \\
\hline \multicolumn{7}{|l|}{ Neonatal outcome } \\
\hline \multicolumn{7}{|l|}{ Early neonatal } \\
\hline Death & $0(0.0)$ & $1(2.3)$ & $0(0.0)$ & $0(0.0)$ & $1(6.2)$ & $0(0.0)$ \\
\hline
\end{tabular}

HELLP-Hemolytic Elevated Liver enzyme and low platelet.

The usual markers of developing countries like poor antenatal care, illiteracy, lack of awareness and poverty in developing countries continues to favor these nightmares of pregnant mothers [8]. Thus, the aim of this study is to highlight the management outcome and factor associated with pregnancy related hypertensive disorder in an Ethiopian hospital.

\section{Materials and methods}

\section{Study setting and period}

This study was conducted from $1^{\text {st }}$ January 2010 to December $1^{\text {st }} 2013$ in Mettu karl hospital. The hospital has 138 health professionals in different disciplines. The number of pregnant mother in the catchment per year is 55,860 . There are a total of 160 beds in all wards of which 47 beds (38 gynacology and 9 in obstetrics) and three delivery coaches.

\section{Study design and participants}

A three years hospital based retrospective study design was implemented to determine management outcome and factor associated with pregnancy related hypertensive disorders. All pregnant mothers who gave birth at Metu karl hospital over the study period (three years) were included for the review.

\section{Instruments and data collection methods}

The data for this study was obtained from admission registration logbooks, delivery registration books and patient charts. The data was collected using a pre-tested check list questioner which was a socio-demographic variables, obstetrics history, sign and symptoms at presentation, laboratory result, maternal and fetal outcomes. The data collectors were given two days training on how to review and abstract the required and pertinent information from the main document. Data collection tools (the checklists) to collect the data from the registration books and client cards was prepared and pretested with similar group as the target group and excluded from the sample. To assure the quality of the data, data collectors was supervised by principal investigator every day.

\section{Ethical statement}

Ethical approval is obtained from Ethical review board of Jimma University, College of Public Health \& Medical Science. Metu karl Hospital gives permission to conduct the study. Then, study participants had also gave informed written consent. The privacy of mothers was kept confidential.

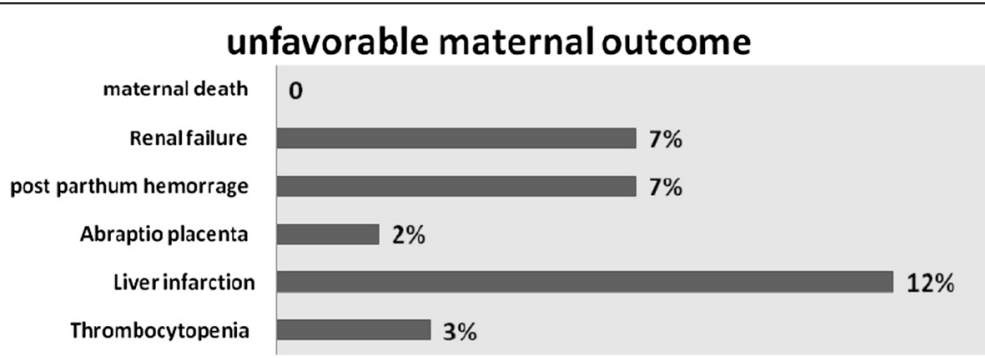

Figure 1 Percentage of mothers with unfovorable outcome $(n=121)$. 


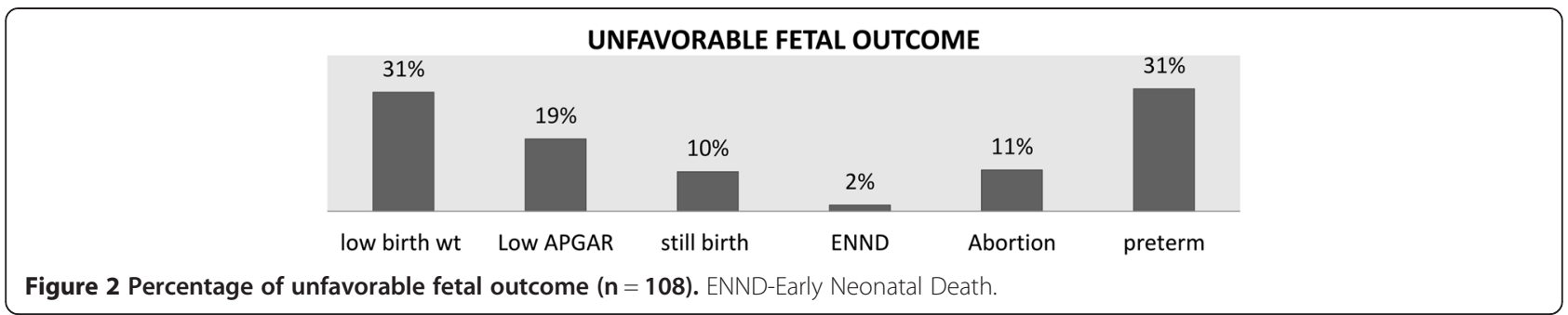

\section{Data analysis}

The collected data were manually checked for completeness and for any inconsistency then coded and entered into SPSS version 16.0 for data processing and analysis. Descriptive, binary and multiple logistic regression analysis were used. On binary logistic regression analysis, a p-value $\leq 0.25$ was used as a candidate for multiple logistic regression analysis. A $95 \% \mathrm{CI}$ and P- value of $<0.05$ was considered statistically significant and crude/adjusted odds ratio calculated.

\section{Result}

\section{Socio demographic characteristics}

A total of 5415 pregnant mothers admitted to Mettu karl obstetrics ward for delivery from January $1^{\text {st }} 2010$ December 30/2013 and their record was reviewed of which 130 mothers were found to have the diagnosis of pregnancy related hypertensive disorder. Among these 121 (93\%) mothers who have a record of HDP were retrieved for further analysis. The minimum and maximum age of the mother were 15 and 39 respectively with a mean and standard deviation of 24.4 (SD \pm 5.12$)$. The majority $100(82.6 \%)$ of the mothers were in the age range between 18 to 34 years. As to their residence and background information, $84(69.8 \%)$ were from outside of Mettu town, 62 (51.2\%) un-booked for antenatal care follow up, and 63 (52.1\%) were primiparous.

Majority $58(47.9 \%)$ of the mother presented to the Hospital with a chief complain of headache. Nearly 87 (71.9\%) of the mother had maximum blood pressure record of $\mathrm{BP} \geq 16 \mathrm{o} / 110$. Sever preeclampsia is the most common hypertensive disorder of pregnancy accounting $35.5 \%$, followed by eclampsia which contributed 19\%, mild preeclampsia $14.9 \%$, HELLP syndrome $12.4 \%$, gestational HTN 13.2\%, and chronic HTN 4.1\% and two patients were superimposed preeclampsia Table 1.

There were eight mothers with HDP complicated with renal failure (6.6\%), nine (7.4\%) with postpartum hemorrhage and two with abruptio placenta and there was no maternal death during the study period (Figure 1).

In this study of all 108 mothers with unfavorable fetal outcomes, the perinatal mortality rate was 120.37 per thousand deliveries and 11 still births yielding the still birthrate of $10.185 \%$. The rate of low and very low birth weight were $24.8 \%$ and $3.3 \%$ respectively and there were 20 (18.5\%) low APGAR score and preterm delivery 34 (28.1\%) among 108 deliveries .there were 2 early neonatal death and 13 (10.7\%) abortion (Figure 2).

As to the management of mothers, 2 (1.7\%) of them were managed conservatively, 38 (31.4\%) with anti-hypertensive,

Table 2 Onset of labor and intervension of mothers with hypertensive disorder of pregnancy

\begin{tabular}{|c|c|c|c|c|}
\hline \multirow[t]{2}{*}{ Variables } & \multicolumn{4}{|c|}{ Type of hypertension (hypertensive disorder of pregnancy) } \\
\hline & Preeclampsia & Eclampsia & Gestational & Chronic \\
\hline \multicolumn{5}{|l|}{ Onset of labor } \\
\hline Spontaneous & $33(55)$ & $15(25)$ & $10(16.7)$ & $2(3.3)$ \\
\hline Induction & $41(70.7)$ & $8(13.8)$ & $5(8.6)$ & $4(6.9)$ \\
\hline Elective Cesarean & $2(66.7)$ & $0(0)$ & $1(33.3)$ & 0. (0) \\
\hline \multicolumn{5}{|l|}{ Mode of delivery } \\
\hline Vaginal & $56(62.9)$ & $19(21.3)$ & $9(10.1)$ & $5(5.6)$ \\
\hline Caesarean section & $11(52.4)$ & $2(9.5 \%)$ & $7(33.3)$ & $1(4.8)$ \\
\hline Forceps/vacuum & $7(77.8)$ & $2(22.2)$ & $0(0)$ & $0(0)$ \\
\hline Destructive & $2(100)$ & $0(0)$ & $0(0)$ & $0(0)$ \\
\hline \multicolumn{5}{|l|}{ How patients managed } \\
\hline Conservatively & $0(0)$ & $0(0)$ & $2(100)$ & $0(0)$ \\
\hline Antihypertensive & $17(44)$ & $2(5.3)$ & $14(36.8)$ & $5(13.2)$ \\
\hline Antihypertensive + anticonvulsant & $59(72.8)$ & $21(25.9)$ & $0(0)$ & $1(1.2)$ \\
\hline
\end{tabular}


Table 3 Binary logistic regression on factors associated with material management outcomes

\begin{tabular}{|c|c|c|c|}
\hline \multirow{2}{*}{$\begin{array}{l}\text { Variables } \\
\text { Address }\end{array}$} & \multicolumn{2}{|c|}{ Management outcomes } & \multirow[t]{2}{*}{ COR $(95 \% \mathrm{Cl})$} \\
\hline & Favorable & Un-favorable & \\
\hline Metu & 12 & 25 & 1 \\
\hline Out metu & 14 & 70 & $2.40(.98-5.88)$ \\
\hline \multicolumn{4}{|l|}{ Parity } \\
\hline Multipara & 12 & 46 & 1 \\
\hline Nullipara & 142 & 46 & $0.91(0.38-2.18)$ \\
\hline \multicolumn{4}{|l|}{ Antenatal care } \\
\hline Yes & 13 & 45 & $0.68(0.28-1.64)$ \\
\hline No & 13 & 50 & 1 \\
\hline \multicolumn{4}{|l|}{ Gestational age } \\
\hline Term & 20 & 55 & 1 \\
\hline Preterm & 5 & 29 & $2.11(0.72-6.20)$ \\
\hline Abortion & 1 & 11 & $4.00(0.49-33.00)$ \\
\hline \multicolumn{4}{|l|}{ Maximum BP } \\
\hline $140 / 90-159 / 109 \mathrm{~mm} \mathrm{Hg}$ & 18 & 16 & 1 \\
\hline$>160 / 110 \mathrm{~mm} \mathrm{Hg}$ & 8 & 79 & $11.11(4.12-29.93)^{*}$ \\
\hline \multicolumn{4}{|l|}{ Urine albumin } \\
\hline Negative & 14 & 7 & 1 \\
\hline Positive & 46 & 54 & $10.88(3.78-31.27)^{*}$ \\
\hline \multicolumn{4}{|l|}{ Length of hospital stay } \\
\hline$<7$ & 7 & 8 & 1 \\
\hline$>$ or $=7$ & 13 & 52 & $2.03(.75-5.54)$ \\
\hline
\end{tabular}

*Significant at $\mathrm{p}$-value $\leq 0.001$ is reference logical reference.

-BP: blood presusure.

and 81 (66.9\%) were given both anti-hypertensive and anti convulsant medications. On the other hand, onset of labor was spontaneous for 60 (49.6\%) of the mother, and induction was made to $58(47.9 \%)$ while elective cesarean delivery was made to $3(2.5 \%)$ of the mother. Majority of the mothers delivered with spontaneous vaginal delivery 89 (73.6\%), cesarean delivery 21 (17.4\%), forceps/vacuum 9 (7.4\%) and two destructive delivery (Table 2).

\section{Predictors of maternal management outcomes of HDP}

Five of the variables were found to be candidates in the binary logistic analysis for the final model. Therefore, a multivariate approach was applied to determine which factors best explained and predict maternal management outcome.

The outcome of the final multiple logistic regression models indicated that address, gestational age and length of hospital stay dropped from the final model. In this analysis maximum blood pressure record has significant statistical association with maternal management outcome of HDP $(\mathrm{AOR}=26,95 \%$ CI: 5.11-132.35, p-value $=0.001)$. The presence of albumin in the urine has statistical association with maternal management outcomes of HDP $(\mathrm{AOR}=37.15$, 95\% CI: 6.58-209.85, p-value $=0.001$. Mothers who had
Proteinuria were more likely to develop unfavorable outcome as compared with mothers with negative Proteinuria (Table 3).

\section{Predictors of fetal management outcomes of HDP}

Seven of the variables were found to be significantly associated in the binary logistic analysis. Therefore, a multivariate approach was applied to determine which factors best explained and predict maternal management outcome. The outcome of the final stepwise multiple logistic regression models indicated that address, antenatal care, maximum blood pressure record, urine albumin, and length of hospital stay dropped from the final model.

In this analysis gestational age has significant statistical association with fetal management outcome of HDP $(\mathrm{AOR}=80.4,95 \%$ CI: 12.68-509.67, p-value $<0.001)$. Preterm newborns are more likely to develop unfavorable fetal outcome as compared with term. APGAR score has significant statistical association with fetal management outcome of HDP (AOR $=22.96,95 \% \mathrm{CI}$ : 3.08-171.21, p-value $=0.002$ ). Newborns with low APGAR score are more likely to develop unfavorable fetal outcome as compared with newborns with good APGAR score (Table 4) 
Table 4 Bivariate on factors associated with fetal management outcomes

\begin{tabular}{|c|c|c|c|}
\hline \multirow[t]{2}{*}{ Variables } & \multicolumn{2}{|c|}{ Management outcomes } & \multirow[t]{2}{*}{ COR $(95 \% \mathrm{Cl})$} \\
\hline & Favorable & Un-Favorable & \\
\hline \multicolumn{4}{|l|}{ Address } \\
\hline Metu & 22 & 15 & 1 \\
\hline Out metu & 38 & 46 & $1.81(0.82-3.98)$ \\
\hline \multicolumn{4}{|l|}{ Parity } \\
\hline Multipara & 29 & 29 & 1 \\
\hline Nullipara & 31 & 32 & $0.97(0.48-1.99)$ \\
\hline \multicolumn{4}{|l|}{ Gestational age } \\
\hline Term & 60 & 15 & 1 \\
\hline Preterm & 3 & 31 & $41.33(11.12-153.68)^{*}$ \\
\hline \multicolumn{4}{|l|}{ Antenatal care } \\
\hline Yes & 32 & 26 & $0.34(0.16-0.73)$ \\
\hline No & 28 & 35 & 1 \\
\hline \multicolumn{4}{|l|}{ Maximum BP } \\
\hline $140 / 90-159 / 109 \mathrm{~mm} \mathrm{Hg}$ & 22 & 12 & 1 \\
\hline$>160 / 110 \mathrm{~mm} \mathrm{Hg}$ & 38 & 49 & $2.06(0.91-4.67)$ \\
\hline \multicolumn{4}{|l|}{ Albimin } \\
\hline Negative & 14 & 7 & 1 \\
\hline Positive & 46 & 54 & $2.08(0.78-5.59)$ \\
\hline \multicolumn{4}{|l|}{ APGAR } \\
\hline$>o r=7$ & 60 & 29 & 1 \\
\hline$<7$ & 3 & 17 & $11.72(3.18-43.23)^{*}$ \\
\hline \multicolumn{4}{|l|}{ Length of hospital stay } \\
\hline$<7$ days & 47 & 32 & 1 \\
\hline$>7$ days & 16 & 26 & $2.39(1.11-5.14)$ \\
\hline
\end{tabular}

*Significant at $p$-value $\leq 0.051$ is reference logical reference. -BP: blood pressure.

\section{Discussion}

Geographic regions of the world reflect various prevalence of hypertensive disorder of pregnancy, from the lowest $1.5 \%$ in Sweden to $7.5 \%$ in Brazil $[12,13]$. In developing countries the pooled incidence of preeclampsia is 3.4\% [14]. However recent analysis of large database from 29 countries, estimates the global distribution of the incidence of all deliveries to be $0.29 \%, 2.16 \%$ and $0.28 \%$ for chronic hypertension, pre-eclampsia and eclampsia respectively [15].

The magnitude of pregnancy related hypertensive disorder in our study was $2.4 \%$. Severe preeclampsia was common in $35.5 \%$ of pregnant mothers and followed by eclampsia. This is not surprising giving the fact that most of the mothers were young ages and with low socioeconomic status. This has been widely investigated in the past decade and now a days being primigravida, living in low socio economic status and young ages are the characteristics of hypertensive disorder of pregnancy [12,16-18]. Placental abruption was as low as $2 \%$ in our case compared to some studies who reported as high as $20 \%$ [19], this might be explained to adequate blood pressure monitoring as no maternal death or intracranial hemorrhage is recorded. In line with many other studies [20], 71.9\% of our mothers had maximum blood pressure record which read $\geq 160 / 110$ and HELLP syndrome in $12.4 \%$ of the cases.

A multivariate approach was applied to determine which factors best explained and predict maternal management outcome. The outcome of the final stepwise multiple logistic regression models indicated that address, antenatal care, maximum blood pressure record, urine albumin, and length of hospital stay dropped from the final model. Other studies also reflected socioeconomic status and antenatal care provision plays the same role as biochemical markers of preeclampsia like urine albumin $[19,21,22]$.

Concerning with the management of our patients the hospital being well equipped and well- staffed and giving service for 24 hours, early presentation of the mothers 
to the hospital and early intervention might contribute to no maternal death. In developed countries pregnancy related acute renal failure has decreased, current estimates are around 1-2.8\% [23], where as in developing countries it is higher and responsible for both maternal and fetal morbidity and mortality [20]. Some setups showed an alarmingly high values to a 36\% [24]. Our investigation indicated the incidence to be $6.6 \%$, which is relatively low this might be due to liberalization with abortion laws, improved health care facilities and more effective measures of care full prevention. On top of this Mettu Karl hospital is well staffed and well equipped hospital compared to other national hospitals in the country.

In our analysis maximum blood pressure record has significant statistical association with maternal management outcome of HDP (AOR = 26, 95\% CI: 5.11-132.35, $\mathrm{p}$-value $<0.001)$. The presence of albumin in the urine has statistical association with maternal management outcomes of HDP (AOR $=37.15$, 95\% CI: 6.58-209.85, $\mathrm{p}$-value $<0.001$. Mothers who had Proteinuria were more likely to develop unfavorable outcome as compared with mothers with negative Proteinuria.

Additionally fetal outcome was affected by gestational age with significant statistical association (AOR $=80.4,95 \%$ CI: $12.68-509.67$, p-value $<0.001)$ as well with the Apgar score $(\mathrm{AOR}=22.96,95 \% \mathrm{CI}$ : 3.08-171.21, $\mathrm{p}$-value $=0.002)$. Preterm newborns are more likely to develop unfavorable fetal outcome as compared with term ones. APGAR score has significant statistical association with fetal management outcome of HDP. Newborns with low Apgar score are more likely to develop unfavorable fetal outcome as compared with newborns with good Apgar score.

In conclusion we say both maternal and fetal outcome is highly dependent on socio-economic status, gestational age and maximum blood pressure of the mother. We recommend effective and competent health service provision through antenatal care and close follow up and management with available resources could improve mortality and morbidity as shown here with low frequencies of complications like renal failure, HELLP syndrome, placental abruption and no maternal death in this referral hospital with a huge catchment area.

\section{Abbreviations \\ HELLP: Hemolysis elevated liver enzyme, and low platlate: \\ APGAR: Appearance, pulse, grimace, activity and reflex; BP: Blood Pressure; HDP: Hypertensive disorder of pregnancy; MmHg: Millimeter mercury.}

\section{Competing interests}

The authors declare that they have no competing interests.

\section{Authors' contributions}

ES was the principal investigator, participated throughout the whole process from data collection to final manuscript preparation. MA Supervised the data collection, check it's consistency prepared the first draft. MT participated in the reviewing the draft, re-write and performing the statistical analysis with NF. NF Conceived of the study, and participated in its design and coordination and helped to draft the manuscript and interpret the result. All authors read and approved the final manuscript.

\section{Acknowledgement}

We all are thankful to the desk and data clerks who had helped in proving all the necessary patient records.

\section{Author details}

${ }^{1}$ Department of Obstetrics/Gynecology and Surgery Coordinating Office, Jimma University, Jimma, Ethiopia. ${ }^{2}$ Department of Psychiatry, Jimma University, Jimma, Ethiopia. ${ }^{3}$ Department of Anesthesia, Jimma University, Jimma, Ethiopia. ${ }^{4}$ Department of Health Education and Behavioral Sciences, Jimma University, Jimma, Ethiopia.

Received: 6 November 2014 Accepted: 19 February 2015

Published online: 15 March 2015

\section{References}

1. Program NHBPE. Report of the national high blood pressure education program working group on high blood pressure in pregnancy. Am J Obstet Gynecol. 2000;183(1):s1-22.

2. Brown MA, Hague WM, Higgins J, Lowe S, McCowan L, Oats J, et al. The detection, investigation and management of hypertension in pregnancy: executive summary. Aust N Z J Obstet Gynaecol. 2000;40(2):133-8.

3. Sibai BM. Diagnosis and management of gestational hypertension and preeclampsia. Obstet Gynecol. 2003;102(1):181-92.

4. Sibai B, Dekker G, Kupferminc M. Pre-eclampsia. Lancet. 2005;365(9461):785-99

5. Reingardiene D. Preeclampsia and eclampsia. Medicina (Kaunas). 2003;39(12):1244-52.

6. Tubbergen P, Lachmeijer AM, Althuisius SM, Vlak ME, Van Geijn HP, Dekker GA. Change in paternity: a risk factor for preeclampsia in multiparous women? J Reprod Immunol. 1999;45(1):81-8.

7. Young BC, Levine RJ, Karumanchi SA. Pathogenesis of preeclampsia. Annu Rev Pathol. 2010;5:173-92.

8. Singhal SR, Deepika A, Nanda S. Maternal and perinatal outcome in severe pre-eclampsia and eclampsia. J South Asian Federation of Obstetrics Gynecol. 2009; 1 (3):25-8.

9. Walker JJ. Pre-eclampsia. Lancet. 2000;356(9237):1260-5

10. Backes CH, Markham K, Moorehead P, Cordero L, Nankervis CA, Giannone PJ. Maternal preeclampsia and neonatal outcomes. J Pregnancy. 2011;2011:214365.

11. Osungbade KO, Ige OK: Public health perspectives of preeclampsia in developing countries: implication for health system strengthening. J Pregnancy 2011., 481095.

12. Yucesoy G, Ozkan S, Bodur H, Tan T, Caliskan E, Vural B, et al. Maternal and perinatal outcome in pregnancies complicated with hypertensive disorder of pregnancy: a seven year experience of a tertiary care center. Arch Gynecol Obstet. 2005;273(1):43-9.

13. Gaio DS, Schmidt MI, Duncan BB, Nucci LB, Matos MC, Branchtein L. Hypertensive disorders in pregnancy: frequency and associated factors in a cohort of Brazilian women. Hypertens Pregnancy. 2001;20(3):269-81.

14. Dolea C, AbouZahr C. Global burden of hypertensive disorders of pregnancy in the year 2000. GBD 2000 Working Paper, World Health Organization: Geneva. http://www.who.int/evidence/bod. 2003b."Global Burden of Obstructed Labor in the Year 2000." GBD 2000 Working Paper, World Health Organization, Geneva. http://www.who.int/evidence/bod, 2003

15. Abalos E, Cuesta C, Carroli G, Qureshi Z, Widmer M, Vogel JP, et al. Pre-eclampsia, eclampsia and adverse maternal and perinatal outcomes: a secondary analysis of the World Health Organization Multicountry Survey on Maternal and Newborn Health. BJOG. 2014;121:14-24.

16. Caritis S, Sibai B, Hauth J, Lindheimer M, VanDorsten P, Klebanoff M, et al. Predictors of pre-eclampsia in women at high risk. Am J Obstet Gynecol. 1998:179(4):946-51.

17. Misra DP, Kiely JL. The association between nulliparity and gestational hypertension. J Clin Epidemiol. 1997;50(7):851-5.

18. Sibai BM. Management of preeclampsia. Clin Perinatol. 1991;18(4):793-808.

19. Hall DR, Odendaal HJ, Steyn DW, Grové D. Expectant management of early onset, severe pre-eclampsia: maternal outcome. BJOG. 2000;107(10):1252-7. 
20. Aali BS, Ghafoorian J, Mohamad-Alizadeh S. Severe preeclampsia and eclampsia in Kerman, Iran: complications and outcomes. Med Sci Monit. 2004;10(4):CR163-7.

21. Gilbert WM, Nesbitt TS, Danielsen B. The cost of prematurity: quantification by gestational age and birth weight. Obstet Gynecol. 2003;102(3):488-92.

22. Onwujekwe O, Uzochukwu B. Socio-economic and geographic differentials in costs and payment strategies for primary healthcare services in Southeast Nigeria. Health Policy. 2005;71(3):383-97.

23. Aggarwal $R$, Mishra $V$, Jasani A, Gumber M. Acute renal failure in pregnancy: Our experience. Saudi J Kidney Dis Transpl. 2014;25(2):450.

24. Ansari MR, Laghari MS, Solangi KB. Acute renal failure in pregnancy: one year observational study at Liaquat University Hospital, Hyderabad. JPMA J Pak Med Assoc. 2008:58(2):61.

\section{Submit your next manuscript to BioMed Central and take full advantage of:}

- Convenient online submission

- Thorough peer review

- No space constraints or color figure charges

- Immediate publication on acceptance

- Inclusion in PubMed, CAS, Scopus and Google Scholar

- Research which is freely available for redistribution 